\title{
Regenerative Injection Therapy (Prolotherapy) for Hip Labrum Lesions: Rationale and Retrospective Study
}

\author{
Ross. A. Hauser ${ }^{*}, 1$ and Amos Orlofsky ${ }^{2}$ \\ ${ }^{1}$ Caring Medical Rehabilitation Services, 715 Lake Street, Suite 600, Oak Park, IL 60301, USA \\ ${ }^{2}$ Albert Einstein College of Medicine, 1300 Morris Park Avenue, F717ND, Bronx, NY 10461, USA
}

\begin{abstract}
Background: Acetabular labral tear is a debilitating condition for which there are few effective non-surgical treatment options. A number of studies in humans and in animal models suggest that the labrum may have a capacity for spontaneous healing, and that therapies that seek to exploit and facilitate this process may be beneficial. Regenerative injection therapies have shown promise in the treatment of several musculoskeletal disorders, but have not previously been applied to labral tear.

Methods: We present an initial case series of 19 patients with labral tear that were treated in our clinic with intra-articular injections of hypertonic dextrose. Patient-reported assessments were collected by questionnaire between 1 and 60 months post-treatment (mean $=12$ months).

Results: All patients reported improvements in pain relief and functionality. Patients reported complete relief of $54 \%$ of recorded symptoms. Improvements did not show dependence on the time between treatment and follow-up. No adverse events were reported.

Conclusions: Regenerative injection therapy (prolotherapy) for acetabular labral tear appears to be a safe and potentially efficacious procedure that merits further investigation as a non-surgical option.
\end{abstract}

Keywords: Acetabular labral tear, chronic pain, regenerative injection therapy, prolotherapy, self report.

\section{BACKGROUND}

Chronic pain of the hip or groin is a common complaint in sports medicine. Hip and groin injuries account for 2 to 9 percent of sports-related injuries [1-7]. In a prospective cohort study, 14 percent of all injuries to European soccer players were to the hip or groin [8]. The time to functional recovery for athletes with these injuries is highly dependent on the injury type. For players in the National Football League, the mean time lost to all hip injuries was 12 days; however, for intra-articular hip injuries, including fracture, subluxation/dislocation and labral tear, the time lost was 94 days [7].

The awareness of labral tears as a potential source of hip and groin pain has grown in recent years due to advances in diagnostic imaging. In a study of 18 sports patients with groin pain, 22 percent had tears of the labrum [9]. In a study of 436 patients with mechanical hip pain, arising in most cases from trauma, 55 percent had labral tears [10]. In a series of 412 arthroscopies in patients with disabling hip pain, labral tear was the major diagnosis in 18 percent [11]. Notably, 74 percent of the labral tears in this study were associated with a non-traumatic etiology, including a degenerative etiology in 45 percent [11], suggesting a

*Address correspondence to this author at the Caring Medical Rehabilitation Services, 715 Lake Street, Suite 600, Oak Park, IL 60301, USA;

Tel: 708-848-7789; Fax: 708-848-7763;

E-mail: JonesM@caringmedical.com potential causative role for labral tear in a broad spectrum of hip pain conditions. Cadaveric studies indicate that acetabular labral tears may accumulate to a high frequency in the general population: 52 percent of 54 cadaveric acetabula, with a mean age of 78 years, contained one or more labral tears [10]. In spite of the high frequency of labral tears, specificity of tears for hip pain has been detected: in a study of 176 patients with unilateral hip pain, 158 had labral tears in the symptomatic hip, and of these only 20 had a contralateral tear in the asymptomatic hip [12].

In addition to the symptomatic complaints of pain and functional impairment, labral tears may be important for degenerative changes in the hip joint. McCarthy et al. detected chondral damage in 73 percent of patients with labral lesions, and observed that chondral damage was more severe in these patients [10]. In 94 percent of these cases, the chondral damage and labral lesion occurred in the same acetabular region. These authors also observed that fullthickness erosion of articular cartilage often occurred in direct continuity with a labral tear, leading them to propose that labral tears represented an early stage of degenerative processes culminating in osteoarthritis [13].

The potential impact of labral pathology on the long-term health of the hip joint, coupled with a growing appreciation of the contributions of the labrum to joint function, has led to increased emphasis on management approaches that maximize labral preservation. Patients are often initially treated conservatively, followed if necessary by surgical treatment. Surgical approaches based on labral resection 
have in recent years been supplemented by more preservative options that involve labral repair or reconstruction [14]. Preservative surgery is not optimal for many patients, however, and it would be valuable to develop preservative non-surgical options that enhance conservative treatment to provide satisfactory outcomes. Regenerative injection therapies have shown promise for functional restoration in a number of musculoskeletal complaints [15], but have not been explored for acetabular labral tears. Here we review and discuss this issue and present initial observations in a group of patients treated with regenerative injection (prolotherapy) for labral tears.

\section{ACETABULAR LABRUM: ANATOMY AND FUNCTION}

The labrum is a ring of tissue that runs circumferentially around the bony rim of the acetabulum. The articular margin of the labrum is directly apposed to the articular cartilage lining the acetabular surface (Fig. 1).

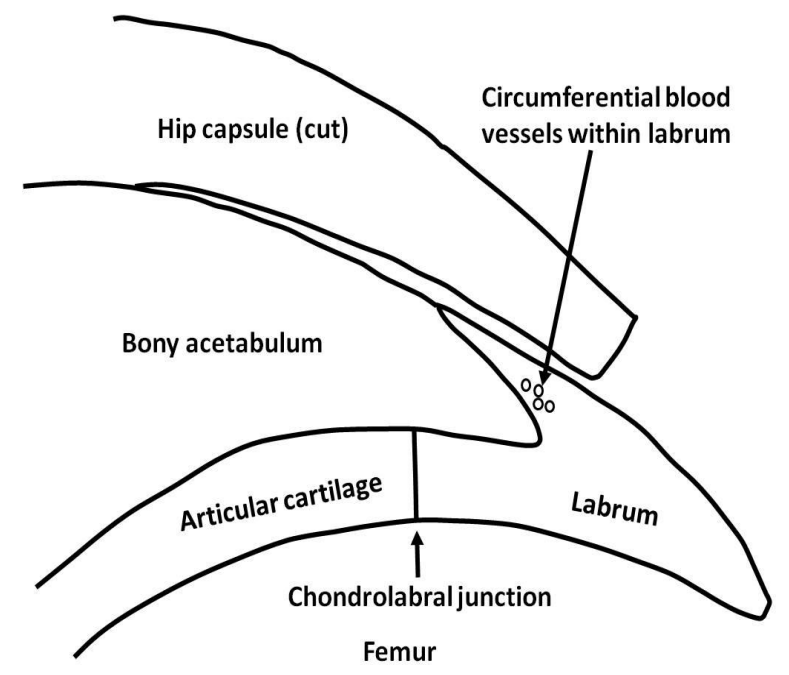

Fig. (1). Anatomic features of the acetabular labrum (adapted from Seldes et al. [16]).

The labrum is not a well vascularized tissue [16-19]. The external third of the labrum, adjacent to the capsular surface, contains clusters of blood vessels that travel circumferentially $[16,17,19]$ (Fig. 1). No vessels are observed in the internal two thirds of the tissue. These studies were carried out, however, in cadavers aged $>40$ years, with a mean age much greater. The fetal acetabular labrum has been shown to be abundantly vascularized [20], similar to the perinatal meniscus [21]. The meniscus displays a gradual age-dependent loss of vascularity, progressing from the internal to the external surface [21]. By analogy, it is possible that the acetabular labrum of younger subjects, including many patients with traumatic labral pathology, is more completely vascularized than the cadaveric subjects that have been reported.

The mechanical function of the labrum is not completely understood. Since the labrum increases acetabular coverage by 28 percent [22] and has biomechanical properties comparable to the meniscus [23], it may serve to enhance joint stability. A stabilizing role is supported by cadaveric studies [24,25]. The labrum may also contribute to joint stability by sealing the joint to maintain intra-articular hydrostatic pressure [26]. This sealing function may also be important to maintain adequate joint lubrication and minimize the friction generated by movement of the femoral head [27]. In addition to its biomechanical functions, the detection of several kinds of proprioceptive nerve endings in the labrum suggests a potential role in proprioception [28].

\section{DIAGNOSIS AND CLINICAL PRESENTATION OF LABRAL TEARS}

Radiographic imaging has come to play a central role in the diagnosis of acetabular labral tears, although arthroscopy remains the gold standard. Plain radiographic images of hips with labral tears are typically normal, while plain MRI can detect labral tear, but with only 30 percent sensitivity and 36 percent accuracy, when compared to arthroscopy [29]. Magnetic resonance arthrography (MRA), in which MRI is enhanced by the intra-articular injection of gadolinium, has become the modality of choice for evaluation. The most recent studies find that MRA has a sensitivity of $93-100$ percent and an accuracy of 93- 96 percent [30-32]. Metaanalysis supports the superior reliability of MRA to plain MRI, although variability and the use of small datasets were noted [33]. The accuracy of MRA may be dependent on training: for both MRA and plain MRI, the accuracy of labral tear diagnosis was 85 percent for musculoskeletal radiologists and 70 percent for general radiologists [34]. The need to distinguish between labral tears and normal variants of sublabral recesses represents a potential pitfall that may limit the accuracy of MRA [35]. Disadvantages of MRA include limited availability and morbidity due to postprocedural pain [36]. CT arthrography provides an alternative [37], although it may be inferior to MRA [38].

While radiographic evaluation is valuable for differential diagnosis of labral tear against other potential sources of hip pain, diagnostic injection of the hip with local anesthetic is sufficient for discrimination of referred pain from pain generated by hip pathology. Pain relief following anesthetic injection is diagnostic for the hip as pain generator with a sensitivity of $88-100$ percent and a specificity of $81-100$ percent [39-41], implying high sensitivity for labral tear, though with likely lower specificity than MRI or MRA. The availability of this simple and inexpensive procedure suggests a potential advantage of non-surgical treatments, such as regenerative injection therapies. For these lowmorbidity therapies, which potentially target both the labrum and other intra-articular lesions, specific diagnosis of labral tear, requiring imaging, may be less critical than accurate diagnosis of the hip generator.

Significant functional limitations are associated with labral tears. In a retrospective review by Burnett et al. of 66 consecutive cases of arthroscopically confirmed labral tear, patients reported limitation of walking distance to 6 blocks or less (36 percent), inability to sit for more than 30 minutes (31 percent) and difficulty in donning shoes and socks (37 percent) [42].

Misdiagnosis is frequent. In the study of Burnett et al., the mean interval from onset of symptoms to definitive diagnosis was 21 months [42]. Thirty-three percent of the patients had been given a total of 18 different diagnoses other than labral tear. Thirty-nine percent had received recommendations for narcotic medication, and surgical intervention at sites other than the hip had been 
recommended to 17 percent. Six percent had actually received these surgeries, without obtaining relief. It is conceivable that the lack of cost-effective, non-invasive options for the management of labral tear is an exacerbating factor in the misdiagnosis of these patients.

\section{TREATMENT}

Regimens of conservative management unfortunately do not provide lasting relief in most cases [43]. These treatments incorporate the concept of facilitating the spontaneous healing of the labral lesion. The failure of conservative approaches is therefore likely related to the limited healing capability of this poorly vascularized tissue, which is further discussed below. It has been proposed that manual procedures, including hip joint tractional maneuvers, may facilitate healing [44]. Studies in support of such approaches are lacking. In theory, treatments that enhance the vascularity or the healing activities within labral tissue, as well as in adjacent involved cartilage, hold promise for the improvement of conservative therapy and the avoidance of surgery. We will later discuss regenerative injection therapy as an approach of this kind.

Patients who fail conservative treatment may be offered arthroscopy, which has become the cornerstone of interventional therapy for labral tear. Initially, surgical treatment, whether open or arthroscopic, focused on simple excision (debridement) of torn labrum. Growing appreciation for the functional importance of the labrum, coupled with concern over the potential contribution of labral defects to eventual osteoarthritic progression, has led to a new emphasis on labral preservation and the development of techniques for arthroscopic repair of labral tears [45, 46]. Typically, detachment of the labrum is followed by acetabular resection to correct femoroacetabular impingement (FAI) and subsequent refixation of the labrum to the rim [47]. A limitation of the repair/refixation procedures is that many labral tears are not eligible for this procedure: these include tears with cleavage planes perpendicular to the margin (radial flaps), which are very frequent [48], as well as tears with degeneration, calcification or ossification of the tissue [45, 46, 49]. In addition, the efficacy of repair for maintaining the sealing function of the labrum may be dependent on the suturing procedure chosen by the surgeon [14]. A recent systematic review of studies comparing labral resection and labral repair [50] concludes that labral preservation appears to produce slightly better outcomes, and one of these studies has been updated to 3.5 years of follow-up with similar outcome [51]).

A systematic review of studies of patient satisfaction following arthroscopy for labral tear found that good-toexcellent results were observed in $68-93$ percent of cases [52]. Positive outcome was strongly dependent on the degree of cartilage degeneration observed intraoperatively: fewer than half of patients with arthritic changes or chondromalacia obtained good results [13, 53]. None of these studies contained controls or a cohort design, and none had a mean follow-up period greater than three years. A more recent study of 97 patients treated for FAI with labral tear had a mean follow-up of 58 months and reported an increase in Christensen nonarthritic hip score from 55 to 84 [54].

Major complications from hip arthroscopy were uncommon in a recent prospective study [55]. However, the authors noted that the extent of iatrogenic damage to chondral or labral tissue was difficult to ascertain. They suggested that the 18 percent of cases in which access was considered difficult might represent an upper limit for iatrogenic damage. Although described by many authors, labral puncture or chondral scuffing during arthroscopy are not usually included among complications and are likely to be underreported [56, 57]. Badylak et al. reported that iatrogenic labral puncture occurred in 20 percent of cases in a consecutive series of 250 hip arthroscopies [58]. Ilizaliturri et al. observed 68 cases of iatrogenic cartilage lesions and one labral puncture in a consecutive series of 100 arthroscopies [59]. While neither of these two studies observed any effect of the iatrogenic injuries on short-term outcome [58, 59], the long-term consequences with respect to potential iatrogenic osteoarthritis or other pathologies are unknown. Labral resection is also a potential source of iatrogenic illness, since cadaveric studies indicate that resection, in contrast to labral repair, results in cartilage consolidation and increased cartilage strain, perhaps due to compromise of joint sealing and pressurization [26].

\section{NEW DIRECTIONS IN LABRAL TEAR TREATMENT}

The development of arthroscopic procedures has been beneficial to large numbers of patients suffering from hip pain. The limitations of these procedures, however, are a stimulus to the exploration of alternative modalities. In spite of its benefits, arthroscopy remains an expensive, invasive procedure whose long-term efficacy and potential iatrogenic effects are not well understood. Many patients with labral tear are not considered eligible for labrum-preserving repair, and labral resection in these patients may result in long-term compromise of labral functionality and health of the hip joint. Finally, patients with cartilage degeneration derive limited benefit from arthroscopy.

A potential alternative to surgery is to exploit and amplify spontaneous healing and repair processes in the hip joint. Current trends in arthroscopy already point in this direction. Labral repair embodies the concept that approximation of cleaved labral fragments may lead to healing and restoration of an intact structure. Labral refixation to the external acetabular surface is founded on the expectation that at least the external third of the labrum is sufficiently vascularized to support a process of healing and bonding to the acetabulum. This expectation is supported by observation of partial healing of an incised and repaired labrum in an ovine model [60]. The authors observed two kinds of healing: 1) a proliferation of fibrovascular scar tissue originating at the capsular labral surface, and 2) formation of new bone at regions of exposed acetabulum. The scar tissue progressed toward the articular labral surface, leaving only a shallow unhealed cleft at the articular side. The authors note that incomplete healing may have been related to the immediate and full weight-bearing permitted to the animals post-surgery. They did not examine spontaneous healing in the absence of arthroscopic repair. These findings 
suggest a potential for labral healing that may extend beyond the vascularized region of normal labrum.

These developments raise the question as to whether it is possible to generate beneficial healing responses in the hip joint without recourse to surgical intervention. The rationale for this approach is built on observations of spontaneous healing in disrupted labrum, both in an animal model and in patients. In the sheep model, resection of the superior one third of the labrum, without repair, induced a regenerative process that led to the replacement of the defect with dense fibrous tissue, of similar triangular shape to normal labrum, in 16 of 18 animals, including 5 of 6 animals at 6 weeks, the earliest timepoint examined [61]. The regenerative process included remodeling of subchondral bone, ingrowth of new blood vessels, and apparent penetration of remodeled bone by scar tissue fibers. The new tissue was approximately 130 percent larger in cross-sectional area than control, shamoperated labrum. Healing occurred in spite of the limitation imposed by full weight-bearing post-surgery. The ovine labrum is notable for its histologic resemblance to human labrum, including restriction of vascularity to the capsular layer $[60,61]$.

Evidence of healing in human labrum was obtained by Seldes et al., who examined labral histology in 55 cadaveric human hips from individuals of unknown symptomatic history [16]. Labral tears were detected in 53 specimens, the majority of which occurred at the chondrolabral junction. Notably, all tears were associated with hypervascularity within the labral substance at the base of the tear adjacent to bone. This was observed even for tears in the internal articular region of the labrum, far from the external capsular layer in which vascularity is normally present. The authors also noted chondrocyte proliferation, as well as hyalinization of labral fibrocartilage along the edges of the defects. These observations strongly suggest the potential for vascular growth and healing responses throughout the human labrum.

The high frequency of labral tear in asymptomatic individuals, implied by the cadaveric studies, has recently been confirmed in a prospective study of 45 volunteers (average age 38 years) [62]. Labral tears were identified in 69 percent of hips by MRI scan. Coupled with the observation of vascular healing responses in cadaveric tears [16], these findings suggest that symptomatic labral tears may represent a subset of tears in which healing responses are suboptimal, perhaps comparable to the two of 18 sheep in which regeneration was not observed [61]. This interpretation provides a plausible conceptual framework for the exploration of regenerative therapy for the diseased hip. The goal of regenerative therapy, in this view, is to enhance the regenerative potential of the labral microenvironment and convert suboptimal responses to the adequate healing that may occur in the asymptomatic population.

\section{PROLOTHERAPY FOR MUSCULOSKELETAL REPAIR}

Regenerative injection therapy may be broadly defined as "the injection of growth factors or growth factor production stimulants to promote regeneration of normal cells and tissue.' [15] Within this group of therapies, the term "prolotherapy" (i.e. proliferative therapy) is applied to the administration of irritant or sclerosant substances with the potential to provoke inflammatory and healing responses. The most common injectants for this purpose are hypertonic dextrose $(12-25$ percent $)$ and sodium morrhuate $(0.1-1$ percent). Anesthetics such as lidocaine are often included in the injectant. The mechanistic basis for the action of these agents is not well defined. In cell culture studies, hypertonic dextrose, the most frequently used injectant, has been shown to enhance the growth factor responsiveness of multiple cell types, including fibroblasts, vascular smooth muscle cells and ligament cells [63-65]. Preclinical studies with sodium morrhuate have demonstrated the anabolic potential of prolotherapy in tendons and ligaments [66-68].

Clinical trials have shown efficacy of hypertonic dextrose for multiple musculoskeletal conditions [69]. Two recent studies, including a randomized controlled trial comparing dextrose injection, saline injection and exercise, have shown efficacy of prolotherapy for improvement of pain and function in knee osteoarthritis [70, 71]. In an RCT of prolotherapy (dextrose + sodium morrhuate) for lateral epicondylitis, Scarpone et al. showed significant gains in pain score and grip strength that persisted for at least one year [72]. An RCT carried out by Yelland et al. compared dextrose prolotherapy, eccentric loading exercise, or combined therapy for Achilles tendinosis. Prolotherapy as monotherapy, and particularly in combined treatment, provided more rapid reductions of pain, stiffness, and functional limitations [73]. The evidence for efficacy of prolotherapy in low back pain is less consistent: a Cochrane review found five high-quality RCTs [74], two of which had positive findings for prolotherapy in combination with other treatments.

In addition to prolotherapy, the injection of platelet-rich plasma, another form of regenerative therapy, has also shown efficacy in the treatment of musculoskeletal disorders, including knee osteoarthritis and lateral epicondylitis [75, 76].

\section{HYPERTONIC DEXTROSE TREATMENT OF LABRAL TEAR: A CASE SERIES}

The evidence that regenerative injection therapy can support connective tissue growth responses and provide clinical benefit with low morbidity in musculoskeletal conditions has encouraged us to explore this therapeutic approach as a cost-effective alternative to surgery for patients with hip pain and labral tear. We describe here our experience with a consecutive series of 19 patients (21 hips) diagnosed with labral tear of traumatic etiology.

\section{METHODS}

\section{Patients}

This study concerns 19 patients ( 7 men and 12 women) out of 22 consecutive patients who presented at our chronic pain clinic with pain in the anterior groin, greater trochanter or buttock region. Three of the 22 patients could not be contacted for final interview. The 22 patients represent all the qualifying patients treated with prolotherapy for hip pain at our clinic from mid-2008 through February 2012. Patients were retrospectively excluded from the study if they had other chronic pain or systemic conditions, were taking antiinflammatory medication, had a history of narcotic use or were under 18 years of age. Patients reported having pain for 
a mean of 26 months prior to visit. All had failed conservative management with physical therapy and exercise. At physical exam, all patients had a positive McCarthy sign and/or a positive internal rotation load/grind test. Labral tear was confirmed by MRI or MRA in 15 out of 21 hips. Six patients chose to forego imaging due to financial concerns. The average age of the patients was $50.9(19-84)$ years. Patient characteristics are summarized in Table 1. This study was conducted in accordance with the guidelines of the Declaration of Helsinki.

Table 1. Patient Characteristics

\begin{tabular}{|l|c|}
\hline \multicolumn{1}{|c|}{ Variable } & Mean \pm SD \\
\hline \hline Age (years) & $50.9 \pm 17.1$ \\
\hline Female (\%) & 63 \\
\hline Duration of pain (months) & $25.7 \pm 29.1$ \\
\hline MRI/MRA performed (\%) & 71 \\
\hline Surgery previously recommended (\%) & 63 \\
\hline Number of treatments & $4.7 \pm 1.9$ \\
\hline Duration of treatments (months) & $11.9 \pm 7.0$ \\
\hline Time since last treatment (months) & $9.9 \pm 8.9$ \\
\hline
\end{tabular}

\section{Intervention}

For dextrose prolotherapy, the area to be treated was anesthetized with 5\% lidocaine cream and cleaned with hydrogen peroxide and Chloraprep. In all cases, the injectant contained $15 \%$ Dextrose, $0.1 \%$ Procaine, $10 \%$ Sarapin and 2 IU human growth hormone (hGH). Sarapin, a pitcher plant extract, is included in almost all prolotherapy injectants in our clinic due to its long history of reported favorable effects for chronic pain [77, 78]. hGH has reported stimulatory effects on chondrocytes that may facilitate joint healing [7981 ], and we routinely include it in prolotherapy injectants for conditions involving cartilaginous or fibrocartilaginous tissue. Hip joints were injected with a total of $50 \mathrm{cc}$ at 38 locations around the hip, including the greater trochanter, intertrochanteric crest, neck of femur, and dorsal ischium. Injected areas included the bony attachments of the ischiofemoral and iliofemoral ligaments, tensor fascia lata, gluteus medius, piriformis, gemellus superior, quadratus femoris, obturator internus, gemellus inferior, and vastus lateralis. The mean number of prolotherapy sessions was 4.8 $(1-8)$. The duration of the treatment period was $3-24$ months (mean 11.9).

\section{Clinical Outcomes}

At final interview, a questionnaire was administered in which patients used a $0-10$ rating scale $(0=$ no pain; $10=$ crippling/severe pain) to assess pre-treatment and posttreatment pain intensity (at rest, during normal activity and during exercise). Patients also used $0-10$ rating scales to assess stiffness ( $0=$ no stiffness; $10=$ extremely stiff $)$, range of motion $(0=$ normal motion; $10=$ no motion $)$, and crunching $(0=$ no crunching; $10=$ extreme crunching with even slight movement). Multiple choice questions were used to assess pre- and post-treatment ability to walk distances and ability to exercise. For walking distance, patients chose between the following intervals: $<50 \mathrm{ft} ; 50 \mathrm{ft}-1$ block; 1 block - $0.5 \mathrm{mi}$; $0.5 \mathrm{mi}-1 \mathrm{mi}$; no restriction. For exercise ability, patients selected one of five options: no compromise ('able to exercise as much as I want'); mild compromise ('able to exercise greater than 60 minutes, but not as much as desired'); moderate compromise ('able to exercise $30-60$ minutes'); severe compromise ('able to exercise 0 - 30 minutes'); total compromise ('unable to exercise'). Patients were also asked how many pills they took for their condition pre- and post-treatment.

\section{Statistical Analysis}

The distributions for baseline values were non-normal by Shapiro-Wilk test. Post-treatment and pre-treatment values were compared by Wilcoxon two-tailed signed rank test. Differences with $p$ values $<0.05$ were considered significant.

\section{RESULTS}

Patient-reported outcomes were obtained at a mean of 12 months after completion of treatment (range $0-60$ months). Significant reductions ( $p<0.001$ ) were observed in pain ratings for pain at rest (mean $\pm \mathrm{SD}$ of $5.0 \pm 2.9$ at baseline $v s$ $0.7 \pm 1.3$ post-treatment), pain during normal activity $(6.8 \pm$ 2.3 vs $1.0 \pm 1.3)$, and pain during exercise $(7.5 \pm 2.8$ vs $1.3 \pm$ 1.7) (Fig. 2). Pain ratings in these three categories were reduced to $13 \%, 15 \%$ and $18 \%$ of their baseline values, respectively. All patients had reduced pain during normal activity and exercise, and 18 patients had reduced pain at rest. Although female patients presented with a significantly longer history of pain (Fig. 3A), no significant gender difference was observed for the response of pain to treatment (Fig. 3B). Pain reduction did not show any dependence on the interval between treatment completion and patient report (Fig. 4). For stiffness, range of motion, crunching and pill consumption, only patients with non-zero baseline values were analyzed. All patients had non-zero baseline for at least one of these categories, and all but six had non-zero baseline for at least two categories. With the exception of two patients who reported no gain for range of motion, all patients with non-zero baseline for these categories experienced gain. For stiffness, range of motion and crunching, baseline vs post-treatment ratings were, respectively, $5.6 \pm 2.6$ vs $2.0 \pm 1.8(\mathrm{p}=0.01) ; 6.4 \pm 2.2$ vs $1.9 \pm 2.1(\mathrm{p}=0.0016) ; 4.5 \pm 2.0$ vs $0.63 \pm 0.92(\mathrm{p}=0.01)$ (Fig. 2). Notably, daily pill consumption for alleviation of symptoms, the most objective of our patient-reported outcomes, was completely eliminated: none of the 11 patients who reported pill use before treatment reported any pill use post-treatment $(\mathrm{p}=0.0036)$ (Fig. 2). No patient reported an adverse result (increased rating) for any outcome. Patient-reported scores are summarized in Table 2.

Patients reported gains in functionality following treatment. All patients who reported walking limitations at baseline experienced improved walking distance. Six of 19 patients $(32 \%)$ reported inability to walk more than 1 block pre-treatment, while after treatment all patients could walk 0.5 miles and 16 of $19(84 \%)$ reported no limit to walking (Fig. 5). Eighteen of 19 patients with compromised ability to exercise at baseline reported improved ability to exercise post-treatment. Six of 19 patients $(32 \%)$ reported a complete 


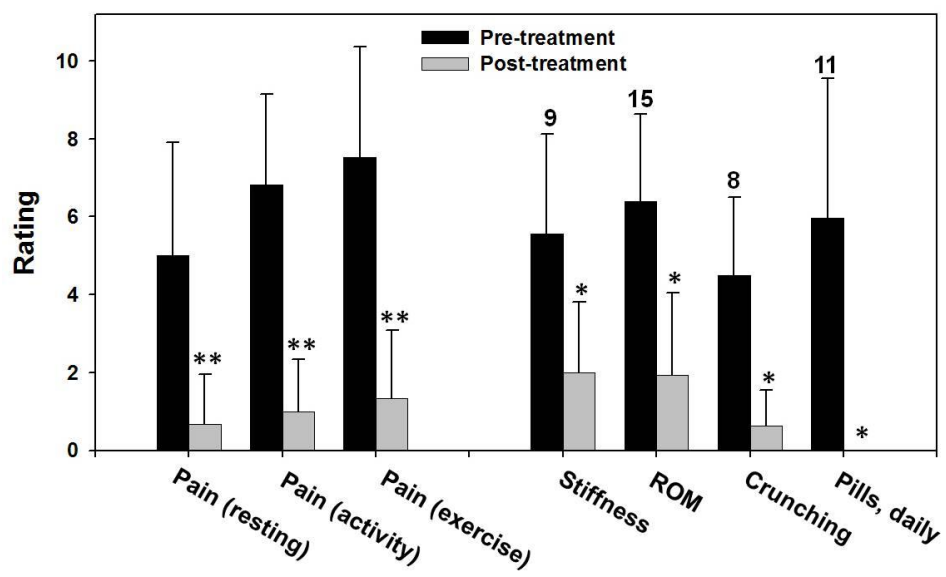

Fig. (2). Patient-reported quantitative outcomes. Patients reported pain, stiffness, range of motion (ROM) and crunching on a 0 - 10 rating scale. For consumption of medications, the ordinate represents the number of daily pills taken. For pain reports, $\mathrm{n}=21 \mathrm{hips}$ (19 patients). For stiffness, ROM, crunching and medications, only reports with non-zero baseline values were analyzed, the numbers of which are indicated above the bars. $* p \leq 0.01, * * p \leq 0.0001$ by Wilcoxon signed-rank test.
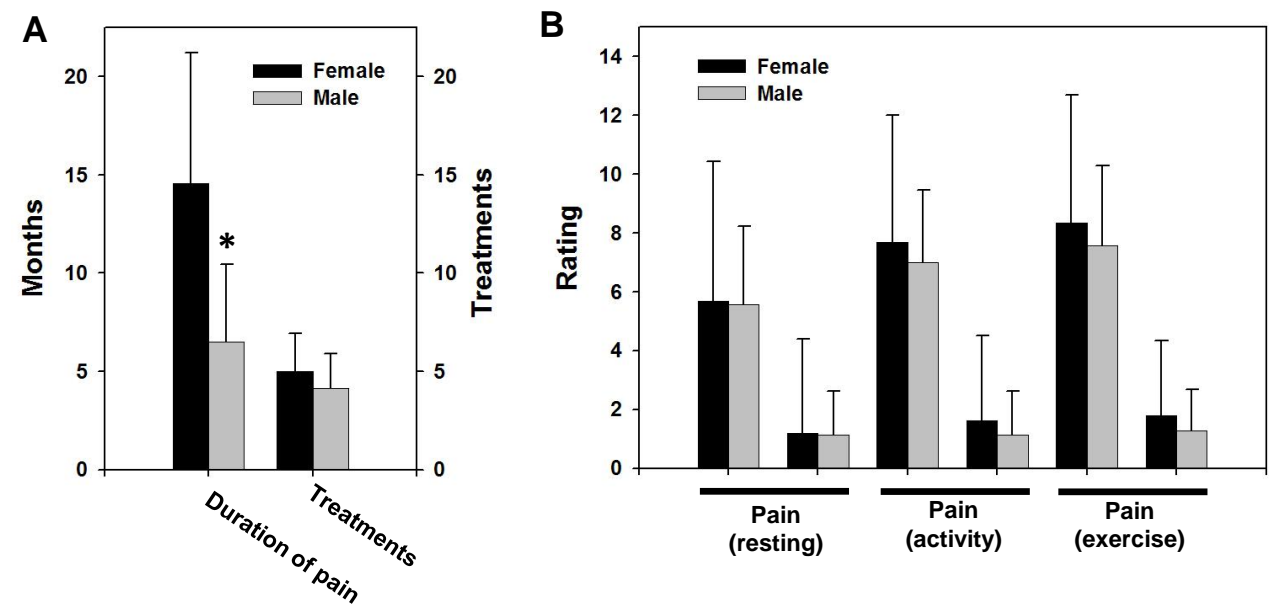

Fig. (3). Gender differences in pain experience and treatment. (A) Gender comparison for duration of pain prior to treatment and number of treatments. $* \mathrm{p}=0.016$. (B) Gender comparison for response of pain to treatment. For each of the three pain categories, the left two bars represent baseline values for patient rating of pain, and the right two bars represent corresponding values after treatment.

inability to exercise before treatment, and none were capable of unrestricted exercise. After treatment, no patient reported complete compromise and 8 of $19(42 \%)$ regained capacity for unlimited exercise (Fig. 5). No adverse outcomes were reported for functionality.

To estimate the frequency with which patients experienced complete relief from a symptom, we combined all the categories on the questionnaire and observed a total of 136 patient reports of a symptom (i.e. a non-zero value or a degree of functional limitation) at baseline. In 73 of these 136 instances (54\%), patients reported complete relief (i.e. the best possible score) post-treatment. Eighteen of 19 patients $(95 \%)$ reported complete relief of at least one symptom, and the mean number of such reports per patient was 3.8. Eleven out of 19 patients $(58 \%)$ reported that they discontinued treatment because they were pain-free (Fig. 6).

\section{DISCUSSION}

This case series represents the first report of a prolotherapeutic approach to the treatment of labral pathology. The results of the study were encouraging, as all 19 patients reported pain reduction and all reported improvement in at least one of two functional categories. All patients expressed a positive view of their treatment on the questionnaire. Although we did not follow individual patients at multiple time points, improvements appeared to be stable during at least the first two years post-treatment, as judged by the lack of time dependence for pain reduction. The treatment was well tolerated and no adverse events were observed.

This pilot study has several limitations. In the absence of controls, we cannot conclude that therapy was effective. In addition, we cannot distinguish among the potential effects 


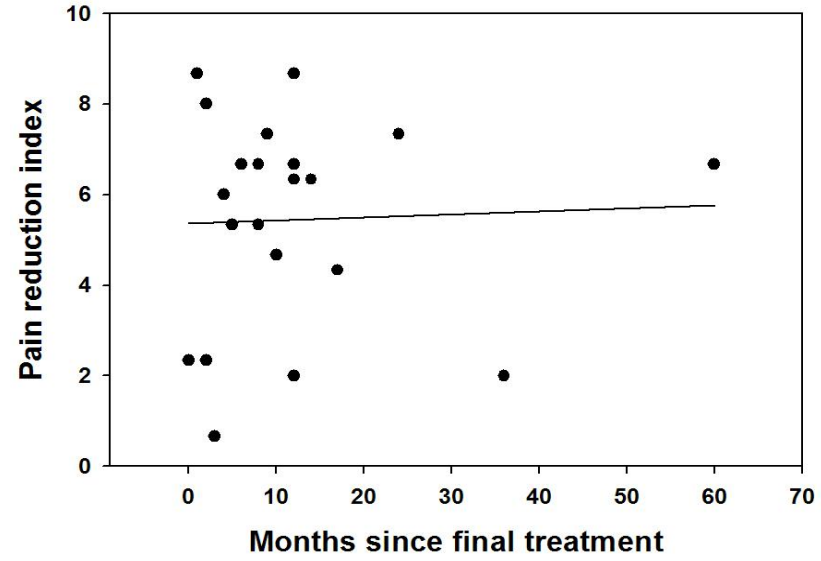

Fig. (4). Time-dependence of pain relief after treatment. A pain reduction index was calculated for each patient by subtracting the post-treatment from the pre-treatment value for each of the three pain categories, and then obtaining the mean of the three differences. The line on the scatter plot represents a least-squares linear regression.

Table 2. Patient-Reported Symptom Scores at Baseline and Post-Treatment (1 - 10 Rating Scale).

\begin{tabular}{|c|c|c|c|}
\hline & $\begin{array}{c}\text { Baseline } \\
(\text { Mean } \pm \text { SD) }\end{array}$ & $\begin{array}{c}\text { Post-Treatment } \\
(\text { Mean } \pm \text { SD) }\end{array}$ & $\begin{array}{c}\text { p Value } \\
\text { (Wilcoxon Test) }\end{array}$ \\
\hline \hline Pain at rest & $5.0 \pm 2.9$ & $0.7 \pm 1.3$ & 0.0001 \\
\hline Pain during activity & $6.8 \pm 2.3$ & $1.0 \pm 1.3$ & 0.0001 \\
\hline Pain during exercise & $7.5 \pm 2.8$ & $1.3 \pm 1.7$ & 0.0001 \\
\hline Stiffness $^{\mathrm{a}}$ & $5.6 \pm 2.6$ & $2.0 \pm 1.8$ & $0.01^{\mathrm{b}}$ \\
\hline Range of motion $^{\mathrm{a}}$ & $6.4 \pm 2.2$ & $1.9 \pm 2.1$ & 0.0016 \\
\hline Crunching $^{\mathrm{a}}$ & $4.5 \pm 2.0$ & $0.63 \pm 0.92$ & $0.01^{\mathrm{b}}$ \\
\hline
\end{tabular}

anly patients with non-zero baseline values included.

${ }^{\mathrm{b}}$ Estimated from tables due to $\mathrm{n}<12$. of the several agents injected (dextrose, sarapin, hGH), as well as the potential effects due to needling and fluid injection. It is also possible that some patient gains represent spontaneous improvement. However, the mean duration of symptoms prior to treatment was 24 months, and we observed no time dependence in symptomatic improvement, which for eight patients occurred in $0-6$ months post-treatment. These findings suggest that much of the gain observed is the result of treatment. Additional limitations include the reliance on post-hoc questionnaires and the paucity of objective outcome measures. The complete absence of pain medication use after treatment provides a degree of objective confirmation of patient benefit. In addition, the expected confounding effect of post-hoc reporting is the exaggeration of gain by inflation of baseline values. However, our data are notable for the high frequency of posttreatment reports of complete symptomatic relief, rather than partial relief from high baseline values, suggesting that post-hoc reporting is not a major confounding factor in the study.

Hypertonic dextrose potentially has multiple effects that may enhance labral healing, including the induction of growth factor production and proliferative responses [63-65], as well as the possible elicitation of inflammatory changes [82] that may promote angiogenic and healing responses. The nature of healing responses in the labrum is still poorly understood, but earlier studies suggest that considerable spontaneous healing occurs $[16,61]$, and that therapies that focus on amplifying and optimizing this spontaneous process may have merit. Given the poor efficacy of current conservative treatment of labral tear, and the risks, failure rate and expense associated with arthroscopy, regenerative therapy may be viewed as a potential adjunct to conservative management that deserves investigation, both in animal models of labral tear and in expanded and controlled clinical studies.

\section{CONCLUSIONS}

Earlier studies of the acetabular labrum indicate a potential for healing responses and provide a rationale for the investigation of regenerative injection therapy for labral

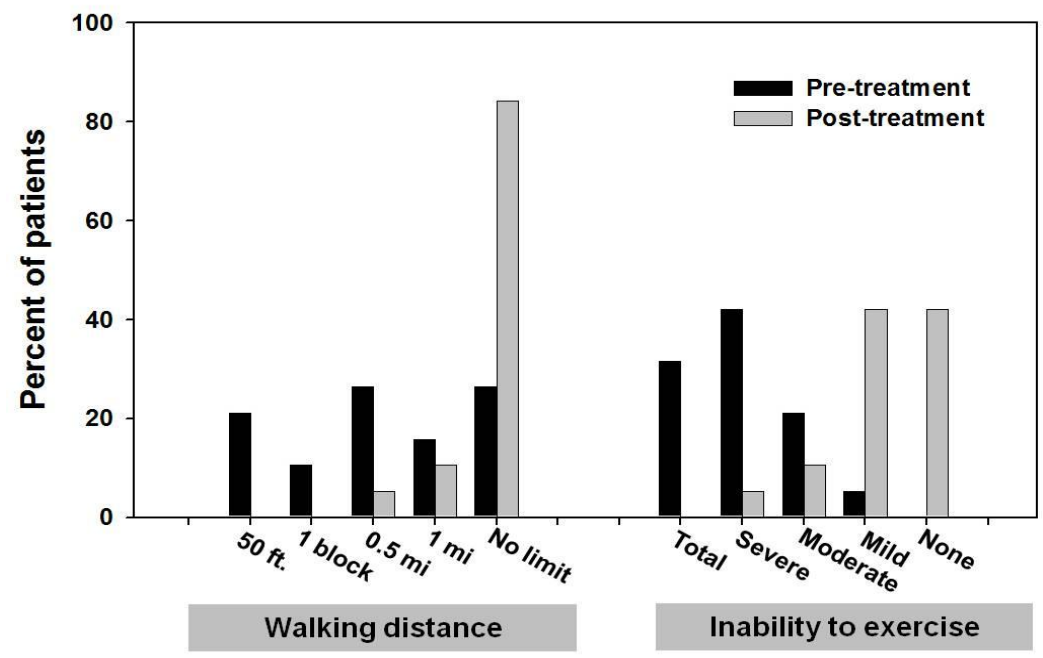

Fig. (5). Patient-reported functional outcomes. Patients chose from five possibilities to describe their maximum walking distance and the degree of compromise in their ability to exercise. $n=19$. 
tear. Our initial experience with hypertonic dextrose in patients with labral tear suggests that the procedure is safe and potentially efficacious. We observed substantial gains in pain relief and functionality in a large majority of patients.

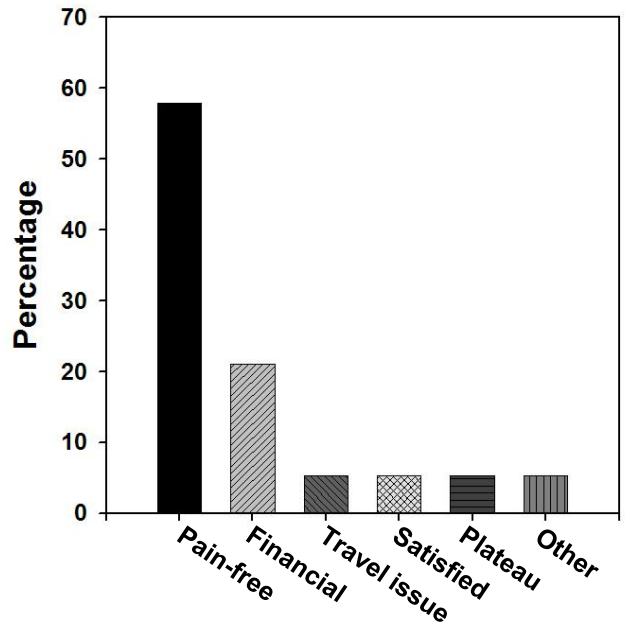

Fig. (6). Reasons for discontinuing treatment. Results are reported as a percentage of total patients $(n=19)$. 'Satisfied' patients reported satisfaction with treatment despite not achieving a painfree state.

\section{AUTHORS' CONTRIBUTIONS}

RAH conceived and executed the study, contributed data and edited the manuscript. AO contributed to analysis and interpretation of the data and wrote the manuscript.

\section{CONFLICT OF INTEREST}

The authors confirm that this article content has no conflict of interest.

\section{ACKNOWLEDGEMENTS}

Declared none.

\section{REFERENCES}

[1] Delee JC, Farney WC. Incidence of injury in texas high-school football. Am J Sports Med 1992; 20: 575-80.

[2] Lynch SA, Renstrom PAFH. Groin injuries in sport - Treatment strategies. Sports Med 1999; 28: 137-44.

[3] Gomez E, Delee JC, Farney WC. Incidence of injury in texas girls' high school basketball. Am J Sports Med 1996; 24:684-7.

[4] Karlsson J, Sward L, Kalebo P, Thomee R. Chronic groin injuries in athletes - recommendations for treatment and rehabilitation. Sports Med 1994; 17: 141-8.

[5] Renstrom P, Peterson L. Groin injuries in athletes. Br J Sports Med 1980; 14: 30-6.

[6] Borowski LA, Yard EE, Fields SK, Comstock RD. The epidemiology of us high school basketball injuries, 2005-2007. Am J Sports Med 2008; 36: 2328-35.

[7] Feeley BT, Powell JW, Muller MS, Barnes RP, Warren RF, Kelly BT. Hip injuries and labral tears in the national football league. Am J Sports Med 2008; 36: 2187-95.

[8] Werner J, Hagglund M, Walden M, Ekstrand J. UEFA injury study: a prospective study of hip and groin injuries in professional football over seven consecutive seasons. Br J Sports Med 2009; 43: 103640.

[9] Narvani AA, Tsiridis E, Kendall S, Chaudhuri R, Thomas P. A preliminary report on prevalence of acetabular labrum tears in sports patients with groin pain. Knee Surg Sports Traumatol Arthrosc 2003; 11: 403-8.
[10] McCarthy JC, Noble PC, Schuck MR, Wright J, Lee J. The role of labral lesions to development of early degenerative hip disease. Clin Orthop 2001; 393: 25-37.

[11] Santori N, Villar RN. Acetabular labral tears: Result of arthroscopic partial limbectomy. Arthroscopy 2000; 16: 11-5.

[12] Huang R., Yusi K, Carty F, Morrison W, Parvizi J. Labral Tears Seen in MRI: What is the Significance?. AAOS 2012 Annual Meeting 2012.

[13] McCarthy J, Noble P, Aluisio FV, Schuck M, Wright J, Lee JA. Anatomy, pathologic features, and treatment of acetabular labral tears. Clin Orthop 2003; 406: 38-47.

[14] Freehill MT, Safran MR. The labrum of the hip: Diagnosis and rationale for surgical correction. Clin Sports Med 2011; 30: 293 315.

[15] Reeves KD, Fullerton BD, Topol G. Evidence-based regenerative injection therapy a (Prolotherapy) in sports medicine. In: Seidenberg PH, Beutler PI, Eds. The Sports Medicine Resource Manual. Amsterdam: Elsevier 2008; pp. 611-9.

[16] Seldes RM, Tan V, Hunt J, Katz M, Winiarsky R, Fitzgerald RH. Anatomy, histologic features, and vascularity of the adult acetabular labrum. Clin Orthop 2001; 382: 232-40.

[17] Petersen W, Petersen F, Tillmann B. Structure and vascularization of the acetabular labrum with regard to the pathogenesis and healing of labral lesions. Arch Orthop Trauma Surg 2003; 123: 283-8.

[18] McCarthy J, Noble P, Aluisio FV, Schuck M, Wright J, Lee JA Anatomy, pathologic features, and treatment of acetabular labral tears. Clin Orthop 2003; 406: 38-47.

[19] Kelly BT, Shapiro GS, Digiovanni CW, Buly RL, Potter HG, Hannafin JA. Vascularity of the hip labrum: A cadaveric investigation. Arthroscopy 2005; 21: 3-11.

[20] Turker M, Kilicoglu O, Goksan B, Bilgic B. Vascularity and histology of fetal labrum and chondrolabral junction: its relevance to chondrolabral detachment tears. Knee Surg Sports Traumatol Arthrosc 2012; 20: 381-6.

[21] Petersen W, Tillmann B. Age-related blood and lymph supply of the knee menisci - a cadaver study. Acta Orthop Scand 1995; 66: 308-12.

[22] Tan V, Seldes RM, Katz MA, Freedhand AM, Klimkiewicz JJ, Fitzgerald RH, Jr. Contribution of acetabular labrum to articulating surface area and femoral head coverage in adult hip joints: an anatomic study in cadavera. Am J Orthop 2001; 30: 809-12.

[23] Ferguson SJ, Bryant JT, Ito K. The material properties of the bovine acetabular labrum. J Orthop Res 2001; 19: 887-96.

[24] Crawford MJ, Dy CJ, Alexander JW, et al. The 2007 Frank Stinchfield Award - The biomechanics of the hip labrum and the stability of the hip. Clin Orthop 2007; 465: 16-22.

[25] Greaves LL, Gilbart MK, Yung AC, Kozlowski P, Wilson DR. Effect of acetabular labral tears, repair and resection on hip cartilage strain: A 7 T MR study. J Biomech 2010; 43: 858-63.

[26] Ferguson SJ, Bryant JT, Ganz R, Ito K. An in vitro investigation of the acetabular labral seal in hip joint mechanics. J Biomech 2003 36: 171-8.

[27] Song Y, Ito H, Kourtis L, Safran MR, Carter DR, Giori NJ. Articular cartilage friction increases in hip joints after the removal of acetabular labrum. J Biomech 2012; 45: 524-30.

[28] Kim YT, Azuma H. The nerve-endings of the acetabular labrum. Clin Orthop 1995; 320: 176-81.

[29] Czerny C, Hofmann S, Neuhold A, et al. Lesions of the acetabular labrum: Accuracy of MR imaging and MR arthrography in detection and staging. Radiology 1996; 200: 225-30.

[30] Chan YS, Lien LC, Hsu HL, et al. Evaluating hip labral tears using magnetic resonance arthrography: A prospective study comparing hip arthroscopy and magnetic resonance arthrography diagnosis. Arthroscopyy 2005; 21: 1250-6.

[31] Toomayan GA, Holman WR, Major NM, Kozlowicz SM, Vail TP. Sensitivity of MR arthrography in the evaluation of acetabular labral tears. Am J Roentgenol 2006; 186: 449-53.

[32] Freedman BA, Potter BK, Dinauer PA, Giuliani JR, Kuklo TR, Murphy KP. Prognostic value of magnetic resonance arthrography for Czerny stage II and III acetabular labral tears. Arthroscopy 2006; $22: 742-7$.

[33] Smith TO, Hilton G, Toms AP, Donell ST, Hing CB. The diagnostic accuracy of acetabular labral tears using magnetic resonance imaging and magnetic resonance arthrography: a metaanalysis. Eur Radiol 2011; 21: 863-74. 
[34] McGuire CM, MacMahon P, Byrne DP, Kavanagh E, Mulhall KJ. Diagnostic accuracy of magnetic resonance imaging and magnetic resonance arthrography of the hip is dependent on specialist training of the radiologist. Skeletal Radiol 2012; 41: 659-65.

[35] Studler U, Kalberer F, Leunig M, et al. MR Arthrography of the hip: Differentiation between an anterior sublabral recess as a normal variant and a labral tear. Radiology 2008; 249: 947-54.

[36] Giaconi JC, Link TM, Vail TP, et al. Morbidity of direct MR arthrography. Am J Roentgenol 2011; 196: 868-74.

[37] Yamamoto Y, Tonotsuka H, Ueda T, Hamada Y. Usefulness of radial contrast-enhanced computed tomography for the diagnosis of acetabular labrum injury. Arthroscopy 2007; 23: 1290-4.

[38] Perdikakis E, Karachalios T, Katonis P, Karantanas A. Comparison of MR-arthrography and MDCT-arthrography for detection of labral and articular cartilage hip pathology. Skeletal Radiol 2011; 40: 1441-7.

[39] Deshmukh AJ, Thakur RR, Goyal A, Klein DA, Ranawat AS, Rodriguez JA. Accuracy of diagnostic injection in differentiating source of atypical hip pain. J Arthroplasty 2010; 25: 129-33.

[40] Pateder DB, Hungerford MW. Use of fluoroscopically guided intraarticular hip injection in differentiating the pain source in concomitant hip and lumbar spine arthritis. Am J Orthop 2007; 36: 591-3.

[41] Faraj AA, Kumaraguru P, Kosygan K. Intra-articular bupivacaine hip injection in differentiation of coxarthrosis from referred thigh pain: a 10 year study. Acta Orthop Belg 2003; 69: 518-21.

[42] Burnett RSJ, Della Rocca GJ, Prather H, Curry M, Maloney WJ, Clohisy JC. Clinical presentation of patients with tears of the acetabular labrum. J Bone Joint Surg 2006; 88A: 1448-57.

[43] Fitzgerald RH. Acetabular labrum tears - diagnosis and treatment. Clin Orthop 1995;311: 60-8.

[44] Schmerl M, Pollard H, Hoskins W. Labral injuries of the hip: a review of diagnosis and management. J Manipulative Physiol Ther 2005; 28: 632 .

[45] Kelly BT, Weiland DE, Schenker ML, Philippon MJ. Arthroscopic labral repair in the hip: Surgical technique and review of the literature. Arthroscopy 2005; 21: 1496-1504.

[46] Murphy KP, Ross AE, Javernick MA, Lehman RA. Repair of the adult acetabular labrum. Arthroscopy 2006; 22(5): 567.e1-3.

[47] Philippon MJ, Stubbs AJ, Schenker ML, Maxwell RB, Ganz R, Leunig M. Arthroscopic management of femoroacetabular impingement - Osteoplasty technique and literature review. Am J Sports Med 2007; 35: 1571-80.

[48] Lage LA, Patel JV, Villar RN. The acetabular labral tear: An arthroscopic classification. Arthroscopy 1996; 12: 269-72.

[49] Schilders E, Dimitrakopoulou A, Bismil Q, Marchant P, Cooke C. Arthroscopic treatment of labral tears in femoroacetabular impingement a comparative study of refixation and resection with a minimum two-year follow-up. J Bone Joint Surg 2011; 93B:102732 .

[50] Tibor LM, Leunig M. Labral resection or preservation during fai treatment? a systematic review. HSS J 2012; 8: 225-9.

[51] Larson CM, Giveans MR, Stone RM. Arthroscopic debridement versus refixation of the acetabular labrum associated with femoroacetabular impingement mean 3.5-year follow-up. Am J Sports Med 2012; 40: 1015-21.

[52] Shindle MK, Voos JE, Nho SI, Heyworth BE, Kelly BT. Arthroscopic management of labral tears in the hip. J Bone Joint Surg 2008; 90A: 2-19.

[53] Farjo LA, Glick JM, Sampson TG. Hip arthroscopy for acetabular labral tears. Arthroscopy 1999; 15: 132-7.

[54] Laude F, Sariali E, Nogier A. Femoroacetabular impingement treatment using arthroscopy and anterior approach. Clin Orthop 2009; 467: 747-52.

[55] Clarke MT, Arora A, Villar RN. Hip arthroscopy: Complications in 1054 cases. Clin Orthop 2003; 406: 84-8.

[56] Papavasiliou AVBNV. Complications of arthroscopic surgery of the hip . Bone Joint Res 2012; 1: 131-44.

[57] Kowalczuk M, Bhandari M, Farrokhyar F, et al. Complications following hip arthroscopy: a systematic review and meta-analysis. Knee Surg Sports Traumatol Arthrosc 2012 [EPub ahead of Print].

[58] Badylak JS, Keene JS. Do iatrogenic punctures of the labrum affect the clinical results of hip arthroscopy? Arthroscopy 2011; 27: 7617 .
[59] Ilizaturri VM, Camacho-Galindo J, Ugalde HG, Ramirez ANE. Cartilage injury caused by hip scope [abstract]. Arthroscopy 2012; 28: e50-1.

[60] Philippon MJ, Arnoczky SP, Torrie A. Arthroscopic repair of the acetabular labrum: A histologic assessment of healing in an ovine model. Arthroscopy 2007; 23: 376-80

[61] Miozzari HH, Clark JM, Jacob HAC, von Rechenberg B, Notzli HP. Effects of removal of the acetabular labrum in a sheep hip model. Osteoarthr Cartil 2004; 12: 419-30.

[62] Register B, Pennock AT, Philippon MJ, et al. Prevalence of hip pathology in asymptomatic subjects: An MRI prospective investigation [abstract]. AAOS 2012 Annual Meeting \#664, 2012.

[63] Fukuda K, Kawata S, Inui Y, et al. High concentration of glucose increases mitogenic responsiveness to heparin-binding epidermal growth factor-like growth factor in rat vascular smooth muscle cells. Arterioscler Thromb Vasc Biol 1997; 17: 1962-8.

[64] Ohgi S, Johnson PW. Glucose modulates growth of gingival fibroblasts and periodontal ligament cells: Correlation with expression of basic fibroblast growth factor. J Periodontal Res 1996; 31: 579-88.

[65] Pugliese G, Pricci F, Locuratolo N, et al. Increased activity of the insulin-like growth factor system in mesangial cells cultured in high glucose conditions. Relation to glucose-enhanced extracellular matrix production. Diabetologia 1996; 39: 775-84.

[66] Liu YK, Tipton CM, Matthes RD, Bedford TG, Maynard JA, Walmer HC. An in situ study of the influence of a sclerosing solution in rabbit medial collateral ligaments and its junction strength. Connect Tissue Res 1983; 11: 95-102.

[67] Maynard JA, Pedrini VA, Pedrinimille A, Romanus B, Ohlerking F. Morphological and biochemical effects of sodium morrhuate on tendons. J Orthop Res 1985; 3: 236-48.

[68] Aneja A, Karas SG, Weinhold PS, Afshari HM, Dahners LE. Suture plication, thermal shrinkage, and sclerosing agents - Effects on rat patellar tendon length and biomechanical strength. Am J Sports Med 2005; 33: 1729-34.

[69] Rabago D, Best TM, Beamsley M, Patterson J. A systematic review of prolotherapy for chronic musculoskeletal pain. Clin J Sport Med 2005; 15: 376-80.

[70] Rabago D, Patterson JJ, Mundt M, et al. Dextrose prolotherapy for knee osteoarthritis: a randomized controlled trial. Ann Fam Med 2013; 11: 229-37.

[71] Rabago D, Zgierska A, Fortney L, et al. Hypertonic dextrose injections (prolotherapy) for knee osteoarthritis: results of a singlearm uncontrolled study with 1-year follow-up. J Altern Complement Med 2012; 18: 408-14.

[72] Scarpone M, Rabago DP, Zgierska A, Arbogast G, Snell E. The efficacy of prolotherapy for lateral epicondylosis: A pilot study. Clin J Sport Med 2008; 18: 248-54.

[73] Yelland MJ, Sweeting KR, Lyftogt JA, Shu KN, Scuffham PA, Evans KA. Prolotherapy injections and eccentric loading exercises for painful Achilles tendinosis: a randomised trial. Br J Sports Med 2011; 45: 421-8.

[74] Dagenais S, Yelland MJ, Del Mar C, Schoene ML. Prolotherapy injections for chronic low-back pain. Cochrane Database of Systematic Reviews 2007; (2): CD004059.

[75] Taylor DW, Petrera M, Hendry M, Theodoropoulos JS. A systematic review of the use of platelet-rich plasma in sports medicine as a new treatment for tendon and ligament injuries. Clin J Sport Med 2011; 21: 344-52.

[76] Steinert AF, Middleton KK, Araujo PH, Fu FH. Platelet-rich plasma in orthopaedic surgery and sports medicine: pearls, pitfalls, and new trends in research. Oper Tech Orthop 2012; 22: 91-103.

[77] Manchikanti L, Pampati V, Fellows B, Bakhit CE. The diagnostic validity and therapeutic value of lumbar facet joint nerve blocks with or without adjuvant agents. Curr Rev Pain 2000; 4: 337-44.

[78] Manchikanti L, Pampati V, Rivera JJ, Beyer C, Damron KS, Barnhill RC. Caudal epidural injections with sarapin or steroids in chronic low back pain. Pain Physician 2001; 4: 322-35.

[79] Chrisman OD. The effect of growth hormone on established cartilage lesions. A presidential address to the Association of Bone and Joint Surgeons, 1974. Clin Orthop Relat Res 1975: 232-8.

[80] Smith RL, Palathumpat MV, Ku CW, Hintz RL. Growth-hormone stimulates insulin-like growth factor-i actions on adult articular chondrocytes. J Orthop Res 1989; 7: 198-207. 
[81] Werther GA, Haynes KM, Barnard R, Waters MJ. Visual demonstration of growth hormone receptors on human growth plate chondrocytes. J Clin Endocrinol Metabol 1990; 70: 1725-31.
[82] Jensen KT, Rabago DP, Best TM, Patterson JJ, Vanderby R. Early inflammatory response of knee ligaments to prolotherapy in a rat model. J Orthop Res 2008; 26: 816-23.

(C) Hauser and Orlofsky; Licensee Bentham Open.

This is an open access article licensed under the terms of the Creative Commons Attribution Non-Commercial License (http: //creativecommons.org/licenses/by$\mathrm{nc} / 3.0 /$ ) which permits unrestricted, non-commercial use, distribution and reproduction in any medium, provided the work is properly cited. 